\title{
Antifungal Action of Ginkgo biloba Outer Seedcoat on Rice Sheath blight
}

\author{
Tae-Seok Oh, Han-Mo Koo, Hei-Ryeo Yoon, Nam-Su Jeong, Yeong-Jin Kim and Chang-Ho Kim* \\ Kongju National University, College of Industrial Sciences
}

(Received on March 24, 2014; Revised on September 24, 2014; Accepted on October 7, 2014)

From study of antifungal actions on the rice sheath blight by using the extract of Ginkgo biloba outer seedcoats, we found that the extracts of Ginkgo biloba outer seedcoats of all treatment concentrations had inhibited the rice sheath blight. Among them, the most effective concentration was $250 \mathrm{mg} / \mathrm{l}$ at which the growth of microbe was $26 \mathrm{~mm}$ and even at the packaging test, when sprayed the $G$. biloba outer seedcoats at the level of 250 $\mathrm{mg} / \mathrm{l}$, the damage rate of the rice sheath blight was identified as $13 \%$. As a result investigating the antifungal activity by separating polysaccharides from $G$. biloba outer seedcoats, it showed that the clear zone of $14 \mathrm{~mm}$ or more was formed at the concentration of $250 \mathrm{mg} / \mathrm{l}$ or higher. Based on these results, we concluded that the G. biloba outer seedcoat is a natural substance with the antifungal activity on the rice sheath blight.

Keywords : antifungal activity, Ginkgo biloba outer seedcoat, pesticide, polysaccharide, sheath blight

Rice is the largest proportional product in agriculture of Korea, presenting high rate of farming area and production amount in comparison to any other agriculture product. The rice had been grown in 1990's in the area of 1 million two hundred ha, and even now it is grown in 1 million ha. However, being affected by the global climate change, the temperature of Korean peninsula had been raised about $1.5^{\circ} \mathrm{C}$ in the past 100 years, with longer spring and summer.

Among the diseases of rice, such as sheath blight is known to have high prevalence in conditions of high temperature and humid (Endo, 1935; Yoshimura, 1955). Lee et al. (2010) had reported in their study on the prevalence of diseases and insect pests, in rice that in 2001, percent top lesion height vs plant height (PLH) had occurred at the

*Corresponding author.

Phone) +82-41-330-1206, FAX) +82-41-330-1209

E-mail) changho@kongju.ac.kr least as $10.2 \%$, whereas it occurred at the most in 2007 as $21.4 \%$, showing gradual increase. When inferring from the report on gradual growth in production, it is expected that the prevalence of sheath blight is likely to increase in the future

In contemporary society, production and consumption of eco-friendly agricultural materials increase continually. Among them, the plant-derived and the oriental herbal medicinal materials contain antifungal substances that are produced for protection against pathogenic microbes. These antifungal substances are made up mainly of organic acids, fatty acids, phenolic compounds such as flavonoids as well as glycoside. To this end, researches on the extract components of natural materials are actively implemented to be used for studies of antifungal materials even in the fields of food, pharmaceutical industry and biotechnology industry, and researches to separate and apply substances identified with excellent antifungal activities and good stability (Han, 2004; Park et al., 2001).

A large number of Ginkgo trees had been planted for landscape in Korea. Its leaves are being utilized as the raw material of pharmaceutical product, while the Ginkgo biloba seeds are used a lot as a food the outer seedcoat, which is usually discarded, causes environment problems due to its foul odor. However, the outer seedcoat being disposed has been known to have strong effects on insect pest and fungal pathogens, and Choi (2000) has reported that the extract of G. biloba outer seedcoat had insect pest effects. Therefore, this study was conducted to test the possibility of utilizing the wasted Ginkgo outer seedcoat as resources of antifungal agent for rice sheath blight.

G. biloba outer seedcoats used in this study were isolated after harvesting Ginkgo tree nuts from the Ginko trees inside the College of Industrial Sciences of Kongju National University located at Daehoe-ri, Yesan-eup, Yesan-gun in Choong Chung Nam-do in October of 2011. The isolated G. biloba outer seedcoat were dried with hot air at $60^{\circ} \mathrm{C}$ for 4 days thereafter crushed using a grinder (HMF-340, Hanil, Korea. The outcome of this process was used as the test sample for extract. As the extract solvent, we used Ethanol 
(HPLC grade, Burdick \& Jackson, USA). We had mixed the powdered test sample of $G$. biloba outer seedcoats and Ethanol in the ratio of $1: 5(\mathrm{w} / \mathrm{v})$ and put the mixture into agitated extraction for 24 hours at the room temperature. Subsequent to this process, we filtrated using filter paper (Whatman, No.2) and performed the vacuum concentration at $45^{\circ} \mathrm{C}$ water bathe using a rotary evaporator $(\mathrm{N}-1000$, Eyela, Japan) to obtain $51 \mathrm{~g}$ of $\mathrm{G}$. biloba outer seedcoat extract. To isolate polysaccharide from the extract, we performed a 100\% HP 20 column chromatography and a $100 \% \mathrm{MeOH}$ from $\mathrm{H}_{2} \mathrm{O}$ respectively and obtained 8 of sub-fractions from a column chromatography. When we screened subfractions for the activity, Fr.3 showed the highest activity. This fraction was then divided into two fractions by performing a $\mathrm{C} 18$ column chromatography.

When we identified the different sugar components of Fr.3-2 that had shown stronger activity through 1H-NMR, anomeric signals were found from 4.0-5.0 mg/1. Sugar backbone-induced oxymethine and oxymethylene were observed while when we analyzed by using the detection: ICS-5000 and column: CarboPacPA10 $(4.5 \times 250 \mathrm{~mm}$, Dionex, Sunnyvale, CA, USA) with CarboPac PA10 cartridge $(4.5 \times 50 \mathrm{~mm})$ it was identified as polysaccharide under the conditions of $\mathrm{NaOH}$ as the perfusion fluid and at the flow rate of $1.0 \mathrm{ml} / \mathrm{min}$.

We had used Rhizoctonia solani Kuhn AG-1(IA) (KACC: 40101) supplied from KACC (Korea Agricultural Culture Collection)as publically announced strain of rice sheath blight. To investigate antifungal capacity of Ginkgo biloba outer seedcoat, we mixed PDA broth at the time of manufacturing them before the culturing media became hardened to make the extract fluids of $G$. biloba outer seedcoat have concentration of $62.5,125,250$ and $500 \mathrm{mg} / \mathrm{l}$. We put each $10 \mathrm{ml}$ of them in petri dish of $9 \mathrm{~cm}$ in diameter, and after checking solidification of them, we took the $R$. solani Kuhn AG-1(IA) disc (diameter $5 \mathrm{~mm}$ ) and mounted on the center of medium, for culturing at $25^{\circ} \mathrm{C}$. After 72 hours, we measured the antifungal activities of $G$. biloba outer seedcoats by measuring diameter of hypha growth rate, and the control was prepared by mixing the hexaconazole emulsion to the same concentration as the extract of $G$. biloba outer seedcoat, and then its antifungal capacity was compared by the same method.

After cultivating $R$. solani Kuhn AG-1(IA), whether the concentration of the mycelia was $1 \times 10^{4} \mathrm{piece} / \mathrm{ml}$ was confirmed using a haematocytometer, and then the test sample was prepared by smearing the cultured $R$. solani Kuhn AG-1(IA) on PDA medium using a spread stick, and the polysaccharide was manufactured so that their concentration became $62.5,125,250$, and $500 \mathrm{mg} / \mathrm{l}$, respectively, and then each the polysaccharide was absorbed on $8 \mathrm{~mm}$ disc paper and the disc papers were completely dried, and then the antifungal activity by concentration was compared by measuring after 36 hours the Clear zone created on the periphery of the disc after that the dried discs were incubated in the incubator at $25^{\circ} \mathrm{C}$ with Rhizoctonia solan being adhered onto the plate medium smeared.

The control plot was prepared by mixing the hexaconazole emulsion to the same concentration as the polysaccharide, and then its antifungal capacity was compared and tested by the same method. The testing for packaging microbicide for the rice sheath blight was implemented at the disease and insect pest observational plot of the Agricultural Technology Center in Seocheon-gun, Choong Chung Nam-do, on August 1st 2013. The officially selected specimen was Saenuri. The top dressing of microbiocide was done twice on August 1 and August 7 by each concentration of Ginkgo biloba outer seedcoats, 62.5, 125 and $250 \mathrm{mg} / \mathrm{l}$ at the disease and insect pest observational plot. As for the control, after we sprayed Hexaconazole emulsion, the damage level was calculated in accordance with the disease and insect pest investigation standards of the rice sheath blight on August 14, 2013, which was based on the research, investigation and analysis criteria for the agricultural science technology. The calculation equation is as follows.

Damage Level $(\%)=\left(3 n_{1}+2 n_{2}+1 n_{3} / 3 N\right) \times 100$

$\mathrm{N}=$ Number of invested number of tiller (NOT), $\mathrm{n}_{2}=$ number of diseased tiller (NDT), $\mathrm{n}_{1}=$ number of diseased tiller (NDT) up to the leaves, $\mathrm{n}_{1}=$ number of diseased tiller (NDT) up to the branch leaves, $\mathrm{n}_{3}=$ number of diseased tiller (NDT) up to the third leaves. All statistical analysis had been done by using Duncan test, which was conducted in use of Duncan SAS 8.0 (Statistical Analysis System).

In current days, the proportion of eco-friendly agriculture is gradually growing and the substances having antifungal actions are extracted from the natural resources and used. The development of agricultural anti-biotic materials includes the development of kasugamycin, polyoxin, validamycin and nikkomycin. These materials being developed are replacing the synthetic organic pesticides. In particular, a new type of antifungal agent is under development toward having less pesticides- related damages for the plants with fast release effects and development of new type of antifungal inducement (Kim, 2003; Kim, 2005).

Ginkgo tree has been planted for landscaping in Korea, and the cultivated area of ginkgo is $0.75 \%$ of the national acreage and total production of ginkgo in 2011 is known 
as 2,081 ton (Korea Forest Service, 2012). However, during production of ginkgo, outer seedcoats are inevitably produced as well. Since there is no application plan for the seedcoats up to now, the farming industry discards the resulting seedcoats in the river and landfill, causing environmental issues associated with the unique foul smell of outer seedcoats, on which often bring civil complaint.

It has been known that because the Ginkgo biloba outer seedcoat that currently has been discarded contains ginkgolic acid, it has the antifungal activity for the tubercle bacillus. Recently, the researches on the antimicrobial activity against several plant diseases have been progressed by using this antifungal activity against various plant diseases, and also its antifungal activity against the plant diseases caused by the fungi began to be known. In this experiment, we had tested the antifungal activity against the rice sheath blight by using G. biloba outer seedcoats, and consequently, the bacterial activity of G. biloba outer seedcoats against the rice sheath blight was identified. The results are as shown in Fig. 1 and Table 1.

As shown in Fig. 1, in the case of Untreated control plot (Fig. 1-A), R. solani Kuhn AG-1(IA) made the hyphae to vigorously grow enough to cover the entire medium in the petri dish of $9 \mathrm{~cm}$ dia., but it was confirmed that in the treated plot that mixed the control plot (Fig. 1-B) and the extract of Ginkgo biloba outer seedcoat (Fig. 1-C, D), the

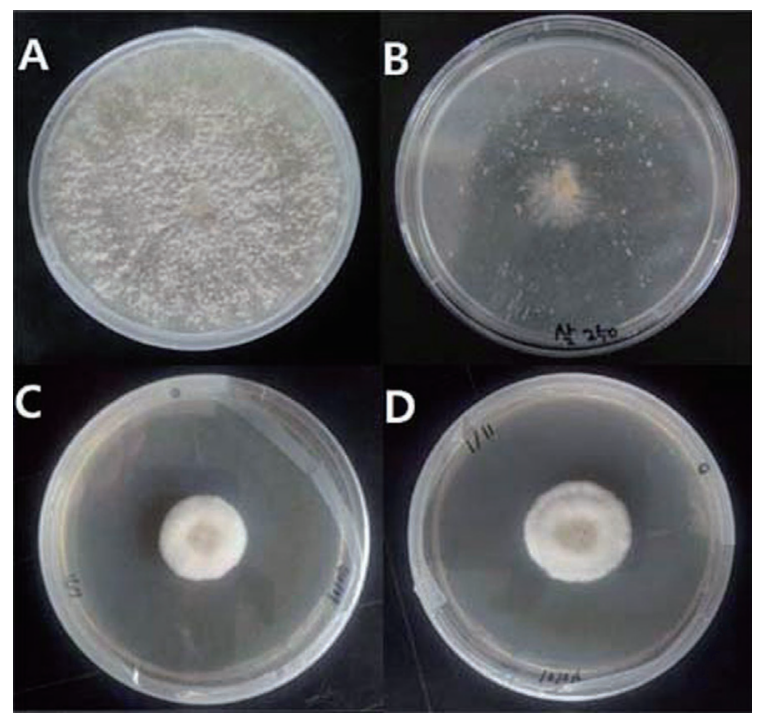

Fig. 1. Growth inhibition effect in Rhizoctonia solani Kuhn AG-1(IA) of hexaconazole emulsion and Ginkgo biloba outer seedcoat extract on PDA culture medium as growth photos from 7th day after inoculation of hypha, A: Untreated control plot, B: hexaconazole emulsion (250 mg/l), C: Ginkgo biloba outer seedcoat extract $(500 \mathrm{mg} / \mathrm{l}), \mathrm{D}$ : treatment levels that G. biloba outer seedcoat extract $(250 \mathrm{mg} / \mathrm{l})$ is mixed. growth of $R$. solani Kuhn AG-1(IA) is inhibited.

After processed the microbial of rice sheath blight on the medium prepared by mixing Ginkgo biloba extracts, it was studied after 7 days. As for the case of no-treatment, the entire petri dish of $9 \mathrm{~cm}$ in diameter was covered by the hypha of rice sheath blight, making impossible to identify the length of hypha growth. As for the control, high levels of antifungal activities were identified in all concentrations, the hypha was not grown above $9 \mathrm{~mm}$ at all at the level of $125 \mathrm{mg} / \mathrm{l}$ and they were $10 \mathrm{~mm}$ at $500 \mathrm{mg} / \mathrm{l}$ as well, while they were $11 \mathrm{~mm}$ and $12 \mathrm{~mm}$ at $250 \mathrm{mg} / \mathrm{l}$ and $62.5 \mathrm{mg} / \mathrm{l} \mathrm{re}-$ spectively, presenting antifungal actions that had almost no statistical significant difference. In case of G. biloba outer seedcoats, it had shown lower level of antifungal activities when compared to the control, but the diameters of hypha were $27 \mathrm{~mm}$ at the concentration of $500 \mathrm{mg} / 1,29 \mathrm{~mm}$ at $250 \mathrm{mg} / \mathrm{l}$ and $52 \mathrm{~mm}$ and $59 \mathrm{~mm}$ of growth diameters were identified from $125 \mathrm{mg} / \mathrm{l}$ and $62.5 \mathrm{mg} / \mathrm{l}$, making our verification on antifungal activities as valid (Table 1).

Park et al. (2011) have reported that the methanol extract of Ginkgo biloba outer seedcoat has the antifungal activity destroying the cell wall against the pathogenic microorganism, and Choi et al. (2013) have reported that the fermented extract of G. biloba outer seedcoat has a high antifungal activity against the fungus that causes various plant diseases. As the results of previous researches as mentioned above, it can be presumed that the G. biloba outer seedcoat Extract has the antifungal substance that inhibits the growth of bacteria and mold. In order to find these antifungal substances, in this experiment, this extract was subdivided to small unit again and the antifungal activity was confirmed by separating the polysaccharide from the extract of G. biloba outer seedcoat based on this.

As the biological activities of Polysaccharides such as

Table 1. Growth diameter of Rhizoctonia solani Kuhn AG-1(IA) hypha according to the added concentration of Ginkgo biloba outer seedcoat extract

\begin{tabular}{|c|c|c|}
\hline \multirow{2}{*}{$\begin{array}{c}\text { Treatment } \\
\text { concentration } \\
(\mathrm{mg} / \mathrm{l})\end{array}$} & \multicolumn{2}{|c|}{ Growth length of hypha $(\mathrm{mm})^{\mathrm{a}}$} \\
\hline & Control & $\begin{array}{c}\text { Ginkgo biloba outer } \\
\text { seedcoat extract }\end{array}$ \\
\hline 62.5 & $12 \pm 0.4 \mathrm{a}^{\mathrm{b}}$ & $59 \pm 3.4 \mathrm{a}$ \\
\hline 125 & $9 \pm 1.3 \mathrm{~b}$ & $52 \pm 4.1 \mathrm{~b}$ \\
\hline 250 & $11 \pm 0.9 \mathrm{a}$ & $29 \pm 2.8 \mathrm{c}$ \\
\hline 500 & $10 \pm 1.7 \mathrm{ab}$ & $27 \pm 3.1 \mathrm{c}$ \\
\hline
\end{tabular}

${ }^{\mathrm{a}}$ Growth diameter of hypha identified on culture medium on 7 day after inoculating Rhizoctonia solani Kuhn AG-1(IA)

${ }^{b}$ Mean separation within columns by Duncan's multiple range test $(\mathrm{P} \leq 0.05)$. 
anti-cancer (Tong et al., 2009; Yang et al., 2005), anti-viral (Yim et al., 2004), and anti-oxidation (Rout and Banerjee, 2007; Tsai et al., 2007; Wang and Luop, 2007) were discovered, it gets attention from the medical field on its antifungal activities, and is being utilized in various aspects

Zhu et al. (2012) had reported that polysaccharides isolated from the mushroom has anti-bacterial activities, and the sugar compositions of antifungal polysaccharide were identified as glucose, rhamnose, mannose or mannose, glucose and galactose, and in this study, it was identified as the polysaccharide that the substance isolated from $G$. biloba outer seedcoats is also composed to basics of glucose as shown in Table 2. However, in contrast to the various activities of polysaccharides, this study did not implement the study on verification of antifungal activities on fungi. However, it was identified polysaccharides isolated from of G. biloba outer seedcoats had antifungal activities for the rice sheath blight, and the result is presented as shown in Table 3. It was identified that the polysaccharides separated from the extract of Ginkgo biloba outer seedcoats have the antifungal activity of a certain level against the rice sheath blight. The hexaconazole emulsion used as a control plot shows high antifungal activity by forming the Clear zone

Table 2. Analysis results of sugar structure in polysaccharide included in the Ginkgo biloba outer seedcoat

\begin{tabular}{lccc}
\hline Sugars/Sample & Sample $(\mathrm{Ng})$ & Sample $(\mathrm{G} / 100 \mathrm{~g})$ & Sample $(\%)$ \\
\hline Fucose & 0 & 0 & 0 \\
Galactosamine & 0.06 & 0 & 0 \\
Glucosamine & 1.68 & 0.08 & 0.08 \\
Galactose & 34.82 & 1.74 & 1.74 \\
Glucose & 489.54 & 24.48 & 24.48 \\
Mannose & 11.81 & 0.59 & 0.59 \\
\hline
\end{tabular}

Table 3. Generation degree of clear zone of Rhizoctonia solani Kuhn AG-1(IA) according to the treatment concentration of control plot and polysaccharide

\begin{tabular}{ccc}
\hline \multirow{2}{*}{$\begin{array}{c}\text { Treatment } \\
\text { concentration } \\
(\mathrm{mg} / \mathrm{l})\end{array}$} & \multicolumn{2}{c}{ Clear zone $(\mathrm{mm})^{\mathrm{a}}$} \\
\cline { 2 - 3 } & Control & Polysaccharide \\
\hline 62.5 & $16 \pm 1.4 \mathrm{a}^{\mathrm{b}}$ & $12 \pm 0.6 \mathrm{~b}$ \\
125 & $15 \pm 1.9 \mathrm{a}$ & $14 \pm 1.1 \mathrm{a}$ \\
250 & $16 \pm 2.1 \mathrm{a}$ & $15 \pm 0.7 \mathrm{a}$ \\
500 & $17 \pm 1.1 \mathrm{a}$ & $15 \pm 1.3 \mathrm{a}$ \\
\hline
\end{tabular}

${ }^{\mathrm{a}}$ Extinction degree of hypha identified at 36 hour after smearing $R$. solani Kuhn AG-1(IA)

${ }^{b}$ Mean separation within columns by Duncan's multiple range test $(\mathrm{P} \leq 0.05)$. more than $16 \mathrm{~mm}$, which is high antifungal activity in the degree that the statistical significant difference according to the concentration is not also present. As shown in Table 3, it was identified that the polysaccharide has the antifungal activity against the rice sheath blight. The polysaccharide formed the Clear zone of $12 \mathrm{~mm}$ in the concentration of $62.5 \mathrm{mg} / \mathrm{l}$ and showed the lowest antifungal activity, but the Clear zone of $14 \mathrm{~mm}$ or more was formed, and the Clear zone of $15 \mathrm{~mm}$ was also formed in $250 \mathrm{mg} / \mathrm{l}$ and 500 $\mathrm{mg} / \mathrm{l}$. The antifungal activity that the polysaccharide has in comparison with the control plot is relatively low, but the antifungal activity of about $88 \%$ in comparison with the control plot was identified, so it is judged that the polysaccharide extracted from G. biloba outer seedcoats have the antifungal activity against the rice sheath blight.

When no treatment group on polysaccharides had displayed high level of antifungal activities but lower level when compared with the control, the non-treatment growth had the medium from which accuracy of number of colonies to the extent to the strain that cause the rice sheath blight and they had covered the medium. In overall, we could not accurately confirm the number of colony of culture, whereas in the control, the growth of microbe that causes the rice sheath blight was inhibited at all of treatment concentration so the colony was not visibly identifiable.

Polysaccharides had shown the most number of colonies at $500 \mathrm{mg} / \mathrm{l}$ as 79 while the lowest at $125 \mathrm{mg} / \mathrm{l}$ treatment

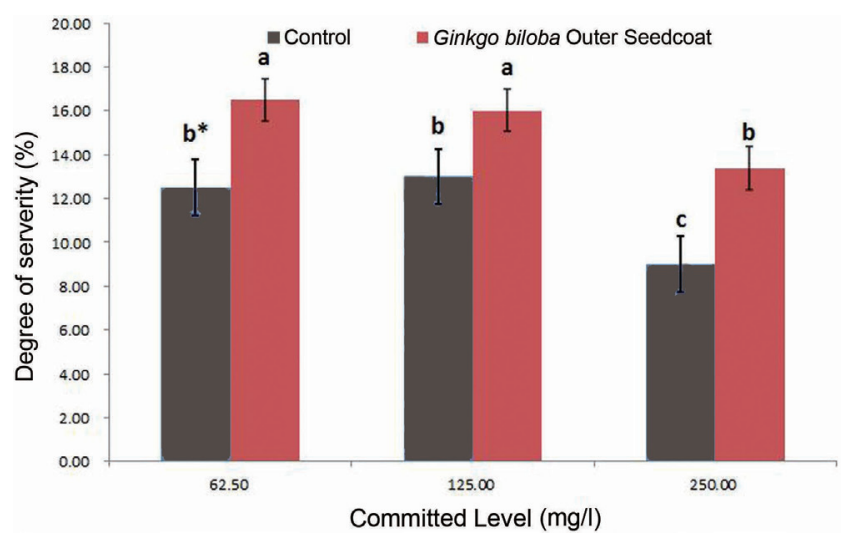

Fig. 2. Packaging control effect of rice sheath blight according to treatment concentration of control disinfectants and Ginkgo biloba outer seedcoat extract control: treatment plot controlled by hexaconazole, G. biloba outer seedcoat: calculation results of damage degree on 14 day after spraying twice in August 1, 7 2013, as treatment plot controlled by mixed extract of G. biloba outer seedcoat ${ }^{a}$ Mean separation within columns by Duncan's multiple range test $(\mathrm{P} \leq 0.05)$. 
concentration as 18 . Also even from $250 \mathrm{mg} / \mathrm{l}$ and $62.5 \mathrm{mg} /$ 1 , less than 30 colonies were identified, presenting lower antifungal activities in comparison with the control but in comparison with the non-treatment, it could inhibit the rice sheath blight effectively so it would be highly utilizable as a disease and insect pesticide.

As for the weather conditions of the day for packaging microbicide test for the rice sheath blight was implemented at the Disease and Insect Pest Observational Plot of the Agricultural Technology Center in Seocheon-gun, Choong Chung Nam-do, on August $1 \mathrm{~m}$ 2013, the average temperature from August 1, 2013 until the final test date August 14 was $28.5^{\circ} \mathrm{C}$, meaning the suitable temperature had been maintained for the prevalence of the rice sheath blight. The damage rate of the non-treatment was identified as $24 \%$, meaning suitable packaging conditions had been formed to carry out the effects of extract of G. biloba outer seedcoats on the rice sheath blight.

The damage rates of the controlled on the final test date, August 14, 2013 were all $\leq 13 \%$ under all treatment conditions, the lowest was $9 \%$ at $250 \mathrm{mg} / \mathrm{l}$ and it was $13 \%$ both at $125 \mathrm{mg} / \mathrm{l}$ and $62.5 \mathrm{mg} / \mathrm{l}$, presenting clear statistically significant difference. In case of the extract of G. biloba outer seedcoats, it showed $13 \%$ at $250 \mathrm{mg} / 1$ presenting lower antifungal actions than the controlled at $250 \mathrm{mg} / \mathrm{l}$ however, no statistically significant difference was identified when compared with $125 \mathrm{mg} / \mathrm{l}$. Nevertheless, the damage rates were presented as $16 \%$ at the highest at the concentration levels of the extract of $G$. biloba outer seedcoats $125 \mathrm{mg} / \mathrm{l}$ and $62.5 \mathrm{mg} / \mathrm{l}$. Given these results, it is possible to consider that the extract of $G$. biloba outer seedcoats contain some antifungal activity on the rice sheath blight and such microbicidal effect is stronger than the synthetic pesticides under current use.

The extract of G. biloba outer seedcoats used in this study was pure extract with no excipients such as subsidiary material. Using this pure extract of G. biloba outer seedcoats by mixing with any material that can increase permeation or other materials with high antifungal activity to enhance the effectiveness of pest control would promise utilization of outer seedcoat extracts as eco-friendly pesticides that can control rice sheath blight. Further studies should be forthcoming for this purpose.

As a result mentioned above, it was identified that the $G$. biloba outer seedcoat has the antifungal activity against the rice sheath blight. Currently, it is judged that entire quantity is being treated as waste because the effective usage for the G. biloba outer seedcoat has been not established due to the unique foul smell, and if the further studies are progressed, the $G$. biloba outer seedcoat will be able to be utilized as basic material of the disinfectant.

\section{Acknowledgment}

The data obtained from this research which was performed as received the research fund from 2013 Yesan Ginkgo Resources Greening Industrialization Agency, which is a part of the local resource industry promotion project of the Ministry of Agriculture, Food and Rural Affairs.

\section{References}

Choi, J. K. 2013. Potent activities of insecticidal components isolated from Ginkgo biloba (L.) leaves and outer seedcoats against aedestogoi (Diptera: Culicidae) larvae. MS Thesis. Chonbuk National University, Jeonju, Korea. p 24-27.

Endo, S. 1933. Effect of sunlight on the infection of the rice plant by Hypochnussasakii Shirai. Ibid. 8:75-48.

Kim, J. B. 2005. Pathogen, insect and weed control effects of secondary metabolites from plants. J. Kor. Soc. Appl. Biol. Chem. 48:1-15.

Kim, J. S. 2003. Development of bio pesticide using higher plantderived natural products. Korea Research Institute of Chemical Technology 1-10:75-97.

Korea Forest Service, 2012, Production of Forest Products p. 14.

Lee, Y. H., Ra, D. S., Yeh, W. H., Chii, H. W., Myung, I. S., Lee, S. W., Lee, Y. H., Han, S. S. and Shim, H. S. 2010. Survey of Major Disease Incidence of Rice in Korea during 1999-2008. Res. Plant Dis. 16:183-190.

Park, S. B. and Cho, G. S. 2011. Antimicrobial activity of extracts and fractions of Ginkgo biloba leaves, seed and outer seedcoat. J. Kor. Soc. Food Sci. Nutr. 40:7-13.

Rout, S. and Banerjee, R. 2007. Free radical scavenging, antiglycation and tyrosinase inhibition properties of a polysaccharide fraction isolated from the rind from Punica granatum. Bioresource Technol. 98:3159-3163.

Tong, H. B., Xia, F. G., Feng, K., Sun, G. G., Gao, X. X., Sun, L. W., et al. 2009. structural characterization and in vitro antitunmor activity of a novel polysaccharide isolated from the fruiting bodies of pleurotusostreatus. Bioresource Technol. 100:1682-1686.

Tsai, M. C., Song, T. Y., Shih, P. H. and Yen, G. C. 2007. Antioxidant properties of water-soluble polysaccharides from Antrodiacinnamomea in submerged culture. Food Chem. 104:1115-1122.

Wang, J. W. and Luo, L. H. 2007. Antioxidant activities of different fractions of polysaccharide purified from Gynostemmapentaphyllum Makino. Carbohydr. Polym. 68:54-58.

Yang, J. H., Du, Y. M., Huang, R. H., Sun, L. P., Liu, H., Gao, X, H., et al. 2005. Chemical modification and antitumour activity of Chinese lacquer polysaccharide from lac tree Phusvernicifera. Carbohydr. Polym. 59:101-107.

Yim, J. H., Kim, S. J., Ahn, S. H., Lee, C. K., Phie, K. T. and Lee, 
H. K. 2004. Antiviral Effects of Sulfated Exopolysaccharide from the Marine Microalga Gyrodiniumimpudicum Strain KG03. Mar. Biotechnol. 6:17-25.

Yoshimura, S. 1955. On The effect of the shading upon the susceptibility of the rice plant to the sheath blight Hypochnussa-
sakiiShirai. Ibid. 16:113.

Zhu, H., Sheng, K. and Yan, E. 2012. Extraction, purification and antifungal activities of a polysaccharide from spent mushroom substrate. Int. J. Biol. Macromolec. 50:840-843. 